\title{
Applications of Cytokeratin Expression in the Diagnosis of Oral Diseases
}

\author{
Archana Sonone ${ }^{1}$, Alka Hande², Madhuri Gawande ${ }^{3}$, Swati Patil ${ }^{4}$ \\ 1,2,3,4 Department of Oral Pathology and Microbiology, Sharad Pawar Dental College, Datta Meghe Institute of Medical \\ Sciences (Deemed to Be University) Sawangi (Meghe), Wardha, Maharashtra, India.
}

ABSTRACT

All mammalian cells have a complex intracytoplasmic cytoskeleton made up of three main structural units and related proteins, tubulin containing microtubules, actin containing microfilaments, and Intermediate Filaments (IF). There are six types of IFs; cytokeratin fibres consisting of type I and type II IFs. Cytokeratins (CK), comprising of collections of IFs that are explicitly communicated by epithelial tissues There are 20 unique polypeptides of CK expressed by epithelium that have been indexed based on their molecular weight (range 40-70 kDa).

CK and associated filaments give a framework to epithelial cells and tissues to maintain their structural integrity. Thus, ensure mechanical resilience, sustain stress, establish cell polarity, and to protect against variations in hydrostatic pressure.

Genetic encoding of cytokeratins shows homogeneous "nucleotide sequence". 54 genes are responsible for encoding of cytokeratin in humans which are congregated on chromosome no. 2. Genetic mutation of cytokeratins is important for pathophysiology of various mucocutaneous disorders, which is mostly autosomal dominant. Patterns and types of cytokeratin expression are very specific and important in tumour typing. Thus, cytokeratin expression is considered as one of the most potent tumour markers of epithelial differentiation in the field of cell biology and surgical pathology.

Oral squamous cell carcinoma is histopathologically graded as well, moderate, poorly differentiated squamous cell carcinoma on the basis of differentiation of neoplastic cells. In case of poorly differentiated oral squamous cell carcinoma, it is critical to identify the phenotype of cell. Thus, differentiation of carcinoma from sarcomas is challenging. As the management protocol and prognosis of carcinoma and sarcoma is varied so diagnosis is mandatory at initial stage. Thus, CK plays an important role in oral squamous cell carcinoma. Apart from this, it has a role in odontogenic pathology and salivary gland pathology.

Expression of these cytokeratins in odontogenesis indicates that they have significant role in embryonic development. Different patterns of expression of keratin help in identification of cells as epithelial cells and also identifies different phases during epithelial differentiation. Antibodies against these cytokeratins can be used to explain the histogenesis and to distinguish the tumours.

Thus, the field of cytokeratins is dynamic and fascinating. Cytokeratins and "corresponding genes", function as etiological components, analytic markers and prognosticators.

\section{KEY WORDS}

Cytokeratin, Oral Diseases, Oral cancer, Odontogenic Tumours
Corresponding Author: Dr. Archana Sonone. Department of Oral Pathology and Microbiology, Sharad Pawar Dental College, Datta Meghe Institute of Medical Sciences (Deemed to Be University) Sawangi (Meghe), Wardha, Maharashtra, India.

E-mail: archanasonone169@gmail.com

DOI: $10.14260 /$ jemds/2021/50

How to Cite This Article:

Sonone A, Hande A, Gawande $M$, et al. Applications of cytokeratin expression in the diagnosis of oral diseases. J Evolution Med Dent Sci 2021;10(04):231-235, DOI: $10.14260 /$ jemds/2021/50

Submission 25-06-2020,

Peer Review 01-08-2020,

Acceptance 08-10-2020,

Published 25-01-2021.

Copyright (C) 2021 Archana Sonone et al. This is an open access article distributed under Creative Commons Attribution License [Attribution 4.0 International (CC BY 4.0)] 


\section{BACKGROUND}

All mammalian cells have a complex intracytoplasmic cytoskeleton made out of three main structural units and related proteins, tubulin containing microtubules, actin containing microfilaments and Intermediate Filaments (IF). There are six types of IFs; cytokeratin fibers consist of type I and type II IFs. In correlation with different sorts of IFs, for example vimentin, desmin, and neurofilaments, Glial Fibrous Acidic Protein (GFAP), cytokeratins are the most complicated. ${ }^{1}$

Cytokeratins (CK), comprise of collections of IF, that are explicitly communicated by epithelial tissues ${ }^{2}$ There are 20 unique polypeptides of CK expressed by epithelium that have been indexed based on their molecular weight (range 40-70 $\mathrm{kDa}$ ).

- Based on molecular weight they are partitioned into low and high molecular forms. ${ }^{3}$

- Based on isoelectric focuses they are isolated into two particular subfamilies.

Type I-acidic and type II-basic /neutral (Isoelectric $\mathrm{pH}$ is a point where protein doesn't move in an electric field and has got least relocating power.) ${ }^{4}$

In general, most low molecular weight keratins will pair with unique high molecular weight keratins; and most basic keratins will pair with an acidic keratin as a 'keratin pair', as described through co-expression. ${ }^{5}$ (Table1)

Not all cytokeratins are incorporated at the same time by any one cell: rather, various subsets of cytokeratins are communicated over the span of terminal differentiation rather, one-of-a-kind subsets of cytokeratins are expressed at some stage in the route of terminal differentiation, in specific levels of development, as well as in epithelia. Thus, all epithelia (simple and complex) can be labelled primarily based upon cytokeratin protein expression.

\section{Various Cytokeratin Phenotypes are Present in Different Types of Epithelia. ${ }^{6}$}

1. Simple epithelium (cuboidal / columnar / one-layered epithelium) which is in adjacent to basement membrane and has a free luminal surface at the apical side of the cell. These cells mainly express CK 8 and 18, and often CK 7, 19 are expressed by duct cells and CK 20 by taste buds.

2. Stratified epithelium is subdivided into two layers (Table 2).

3. Combined epithelium with a high cell turnover express $\mathrm{CK}$ $6 \& 16$.

4. Glandular epithelium expresses CK 18.

\section{Functions of Cytokeratins}

- Cytokeratins is the main component where it influences the architecture and regulate the mitotic activity of the epithelial cells. ${ }^{7}$

- cytokeratins and associated filaments give a framework to epithelial cells and tissues to maintain their structural integrity, ensure mechanical resilience, sustain mechanical stress, establish cell polarity and to protect against variations in hydrostatic pressure 8
- cytokeratins and its fibers are engaged with, cell transport, cell compartmentalization, cell signalling and cell differentiation. ${ }^{9}$

- Cytokeratin filaments additionally impact cell metabolic cycles by directing protein synthesis and cell growth. ${ }^{10}$

\section{CYTOKERATINS AND DISEASE}

The genetic encoding of cytokeratin has the homogeneous "nucleotide sequence", 54 genes are responsible for encoding of cytokeratin in humans which are congregated on chromosome no. 2.11 There is difference in clustering of acidic type I and basic type II cytokeratins. Acidic type I is on chromosome 17, whereas basic type II on chromosome 12 . The genetic mutation of cytokeratins is important for pathophysiology of various mucocutaneous disorders, which are mostly autosomal dominant. The genetic mutation is results in either complete absence of cytokeratin filaments or their structural assembly. This further characterized by involvement of particular epithelial cells which consequences in expressing mutated protein and their vulnerability in disease. (Table 3)

\section{White Sponge Nevus}

White sponge nevus was first described by Cannon in 1935 it is also called as Cannon's disease or familial white folded dysplasia. It is having an autosomal dominant trait and is characterized by benign leukokeratotic lesions of early onset with periods of remissions and exacerbations. ${ }^{12}$ It is caused due to mutation in the gene encoding for $\mathrm{K} 4 / 13$ that is expressed in the spinous cell layer of non-keratinized mucosa of the oral cavity.

\section{Epidermolysis Bullosa Simplex (EBS)}

It is a "mechanobullous genodermatosis" which is caused by mutations in the genes "KRT5 and KRT14" encoding the basal epidermal keratins 5 (K5) and 14 (K14). Literature revels that mutation of KRT5 and KRT14 having correlation between the location of the mutation and the severity of the related EBS phenotype. ${ }^{13}$ There are three major clinical subtypes of EBS present depending on onset, distribution and severity of skin blistering.

\section{Pachyonychia Congenita (PC) (Greek-Thick Nails from Birth)}

This is a rare autosomal dominant disorder caused as a result of mutation in the gene encoding for K6/16 and K17 which is typically affects the palmoplantar skin and nails, hair and often the oral mucosa, teeth tongue, larynx. ${ }^{14}$

\section{Cytokeratin Expression in Malignancy}

During development, the pattern of cytokeratin is specific to embryonic stage to adulthood and further maturation of the tissues. The carcinomas are malignant epithelial tissue tumours. During progression and differentiation of these tumours, the malignant epithelial cells retain their phenotypes which is characterized by the expression of cytokeratin. The 
patterns and type of cytokeratin expression is very specific and important in tumour typing. Thus, the cytokeratin expression is considered as one of the most potent tumour markers of epithelial differentiation in the field of cell biology and surgical pathology.

In most of the cases, conventional methods are used for routine diagnosis of tumours. But there are some special cases are present which required some advance modified techniques such as immunohistochemistry studies in order to attempt accurate diagnosis.

Cytokeratin typing has great value of in phenotyping of the tumours, also in it is having importance in identification of origin of tumours where the primary site is not known. Hence accurate diagnosis of these type of cases through keratin typing will be helpful for the tumour specific-therapeutics protocol which is presently being used. In current practice antibodies against cytokeratin are useful for the differentiation of epithelial malignancies from connective tissue malignancies such as lymphomas, spindle cell sarcoma, and carcinosarcoma.

\section{APPLICATIONS OF “CYTOKERATIN EXPRESSION" IN HEAD \& NECK TUMOURS}

1. Undifferentiated nasopharyngeal carcinomas vs. lymphoma

2. Spindle cell carcinoma vs. sarcoma

3. Poorly differentiated carcinoma vs. large cell lymphoma

\section{Potential Applications of Cytokeratins in Oral} Epithelial Dysplasias and Oral Cancer

Unique correlation present between cytokeratin expression and phase of epithelial "differentiation". Evaluation by using monospecific cytokeratin antibodies have shown distorted cytokeratin expression in "oral premalignant and malignant lesions" indicating unusual differentiation. Differential expression of various cytokeratins is widely used in routine diagnostic pathology for accurate classification of epithelial malignancies. ${ }^{19}$ Various studies have been done using antikeratin antibodies, in premalignant and malignant oral lesions. Some salient points from these studies are:

- Expression of CK 19 in the "suprabasal epithelium" is strongly associated with "potential malignancy".

- Keratin 13 is lost in areas with cellular atypia, complete loss of CK13 in the "prickle cell layer" is a significant immunohistochemical observations in diagnosis of premalignant and malignant oral lesions.

- Keratin 19 expression is increased in oral premalignancy but also in hyperplastic lesions and is therefore not specific for premalignancy.

\section{Potential Applications in Salivary Tumours}

Identification of oral cancers, particularly carcinomas arising from non-keratinizing squamous mucosa and tumours of the salivary glands in general is problematic. The correct identification of such a tumour, particularly identification of origin is important. Keratin immunohistochemistry in such areas plays a major role. The accessibility of monospecific antibodies to all the keratins of simple epithelia gives an opportunity to analyse the keratin expressions in myoepithelial cells, acinar and salivary ductal. (Table 4)

In salivary gland pathology, there has limited applications in cytokeratin profiling. While non-specifically it assists in describing "dual luminal-abluminal differentiation". Salivary glands tumours are classified into two main group: tumours arise from "stratified epithelium (basaloid squamous cells carcinoma, myoepithelioma, pleomorphic adenoma, mucoepidermoid carcinoma and adenoid cystic carcinoma)", and tumours that derived from "simple epithelia (acinar cell carcinoma, monomorphic adenocarcinoma, adenocarcinoma NOS)". The tumours which arise from stratified epithelium express CK14 and CK19, whereas tumours derived from simple epithelia does not express it. Myoepithelial cells express CK14, hence salivary glands tumour having myoepithelial cells are usually positive for CK14. These tumours consist of pleomorphic adenoma, adenoid cystic carcinoma and benign or malignant myoepithelioma. (Table 4)

\section{Potential Applications in Odontogenic Tumours and Cysts}

In the literature, different patterns of cytokeratin expression in odontogenic epithelium have been described in a general manner. In the immunohistological study it was observed that CK14 and CK 19 are expressed in the epithelial cells of tooth germs and in the remnant of dental lamina, with some variability in their expression patterns, depending on the stage of "odontogenesis". The CK14 and CK19 generally expressed in inner enamel epithelium of dental organ, and their expression differ in early bell stage and advanced bell stage. It was observed, that CK 14 was strongly positive in early bell stage and CK 19 was weakly expressed, which was opposite in advanced bell stage.

Expression of these cytokeratin in odontogenesis indicates that they have very important role in embryonic development of dental organ. Different patterns of expression of keratin allocate identification of cells as epithelia cells and also identification different phases during epithelial differentiation. Antibodies against these cytokeratins used to explain the histogenesis and to distinguish the tumours. There are numerous studies carried out in past, which revealed that CK14 and CK 19 have been used to identify the odontogenic epithelium. Thus, cytokeratin CK 14, and CK 19 are utilized as diagnosis and prognostic markers in different tumours of epithelial origin. So, it is not only used for identification of the cell phenotype, different phases of epithelia differentiation but also to characterization of tumours.

\begin{tabular}{|cc|}
\hline & Cytokeratins (CK) \\
\hline Type I (Smaller) & Type II (Larger) \\
Acidic & (Basic/ Neutral) \\
(A' Group) & (B' Group) \\
(9-20) CK & (1-8) CK \\
\hline & Table 1. Cytokeratin \\
\hline
\end{tabular}

\begin{tabular}{|cccc|}
\hline Layers & Keratinizing & Non-Keratinizing & Transitional \\
Basal Cell Layer & CK5 and 14 & CK5 and 14,19 & CK 4 \& 13 \\
Suprabasal Layer & CK 1 and 10 & CK 4 and 13 & CK 7, 8, 18, \\
\hline \multicolumn{4}{|c|}{ Table 2. Cytokeratin in Different Layers of Stratified Epithelium } \\
\hline
\end{tabular}

In the literature cytokeratin expression in odontogenic cyst, specifically radicular cyst, Dentigerous Cyst (DC) and 
Odontogenic Kerato Cyst (OKC) have been extensively studied but no as such difference have been observed. ${ }^{29}$ In various studies there was strong expression of CK 1/10/11 in OKC, whereas in DC and radicular cyst were negative. The lining of OKC shows strong positivity for CK 16 which is suggestive of high proliferative activity. Some of the literature studies shows thar CK17 and CK 19 are consider as valuable marker to distinguish OKC from other odontogenic cyst (CK 17 and CK 19 expression (93\%) in OKC whereas in radicular cyst and DC, CK 17 expression (37\%), and CK expression 19 was $43 \%$ ).

\begin{tabular}{|c|c|c|c|c|}
\hline Diseases & $\begin{array}{c}\text { Oral } \\
\text { Manifestations }\end{array}$ & $\begin{array}{l}\text { Histopathological } \\
\text { Features }\end{array}$ & $\begin{array}{c}\text { Main } \\
\text { Expression } \\
\text { Patterns }\end{array}$ & Keratin \\
\hline $\begin{array}{l}\text { White spongy } \\
\text { nevus } 15,16\end{array}$ & $\begin{array}{l}\text { "symmetrical } \\
\text { asymptomatic, } \\
\text { thickened white, } \\
\text { velvety, diffuse or } \\
\text { corrugated plaques } \\
\text { affecting buccal } \\
\text { mucosa bilaterally" }\end{array}$ & $\begin{array}{l}\text { "Epithelial hyperplasia } \\
\text { and hyper } \\
\text { parakeratosis } \\
\text { Perinuclear } \\
\text { condensation of keratin } \\
\text { tonofilaments in the } \\
\text { superficial layers of } \\
\text { epithelium" }\end{array}$ & $\begin{array}{l}\text { Mucosal } \\
\text { stratified } \\
\text { epithelium } \\
\text { (Prickle cell } \\
\text { layer) }\end{array}$ & CK4, CK13 \\
\hline $\begin{array}{l}\text { Epidermolysis } \\
\text { bullosa } \\
\text { simplex }{ }^{13}\end{array}$ & $\begin{array}{l}\text { "mild involvement- } \\
\text { gingival erythema, } \\
\text { tenderness, recession } \\
\text { and reduction in } \\
\text { depth of buccal } \\
\text { vestibule" }\end{array}$ & Intraepithelial clefting & $\begin{array}{l}\text { Basal cells of } \\
\text { epithelium }\end{array}$ & CK5, CK14 \\
\hline $\begin{array}{l}\text { Pachyonychia } \\
\text { congenital } \\
\text { (Jadassohn } \\
\text { Lewandowsky } \\
\text { type). }{ }^{17}\end{array}$ & $\begin{array}{c}\text { Hyperkeratosis of } \\
\text { oral } \\
\text { mucosa }\end{array}$ & $\begin{array}{l}\text { "Hyper parakeratosis } \\
\text { and acanthosis with } \\
\text { perinuclear clearing of } \\
\text { the epithelial cells" }\end{array}$ & $\begin{array}{l}\text { Mucosal } \\
\text { stratified } \\
\text { epithelium }\end{array}$ & CK16 \\
\hline
\end{tabular}

\begin{tabular}{|cc|}
\hline Cytokeratins in Salivary Epithelia & Distribution \\
CK 14 & "Basal cells (ductal nonluminal cells) and \\
CK 18,19 & Myoepithelial cells" \\
CK 7, 8, 18, 19 & "Epithelium elements of salivary gland" \\
CK 8,18 & Luminal duct cells \\
\hline Table 4. Cytokeratin Distribution in Salivary Epithelia ${ }^{22}$ \\
\hline
\end{tabular}

\begin{tabular}{|cc|}
\hline Cytokeratin & Expression \\
CK 14 & Adenomatoid Odontogenic tumour (AOT) \\
"CK 13, 14, 19" & Ameloblastoma \\
"CK 14, CK 7*, CK 13*, CK 19*" & Calcifying epithelial odontogenic tumour (CEOT) \\
"CK 13, CK14, CK 7*" & Ameloblastic fibroma \\
"CK 7, 14" & Odontoma \\
\hline Table 5. Cytokeratin Expression in Odontogenic Tumours \\
\hline *Expressed seldomly & \\
\hline
\end{tabular}

\section{CONCLUSIONS}

CKs are very sensitive markers for diagnosis of carcinomas \& are generally utilised for distinguishing epithelial malignancy with non-epithelial malignancies such as lymphomas, sarcomas, and melanoma. But recently it was observed that expression of CK was not restricted to the carcinoma. The literature revealed that in other sarcomas, including malignant fibrous histiocytoma, chondrosarcoma, osteosarcoma, and malignant peripheral nerve sheath tumours CK expression is rare.

It is important to understand that immunoreactivity \& true antigen expression are not necessarily same. There are several theoretical factors which are responsible for false positive immunostaining of cytokeratin expression. It includes utilization of antibodies at high concentrations, potentially changed specificities subsequent to the use of heat-induced "epitope retrieval techniques" (antigen-retrieval) and the cross reactivity of anti-cytokeratin antibodies with other proteins.
CKs are biologically significant by virtue of their correlation with cellular differentiation. These proteins are relatively resistant to degradation; thus, show incredible antigenic expression. The application of CK in oral sciences has enlarged the skyline of diagnostic pathology.

Financial or other competing interests: None.

Disclosure forms provided by the authors are available with the full text of this article at jemds.com.

\section{REFERENCES}

[1] Lodish H, Berk A, Zipursky S, et al. Movilidad y forma de la célula I: microfilamentos. EnBiologíacelular y molecular.

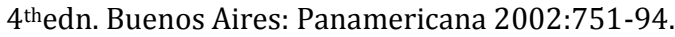

[2] Anderton BH. Intermediate filaments: a family of homogenous structure. Journal of Muscle Research and cell Motility 1981;2(2):141-66.

[3] Moll R, Franke WW, Schiller DL, et al. The catalog of human cytokeratins: patterns of expression in normal epithelia, tumours and cultured cells. Cell 1982;31(1):1124.

[4] Eichner R, Bonirz P, Sun TT. Classification of epidermal keratins according to their immunoreactivity, isoelectric point, and mode of expression. Cell Biol 1984;98(4):138896.

[5] Hatzfeld M, Franke WW. Pair formation and promiscuity of cytokeratins: formation in vitro of heterotypic complexes and intermediate-sized filaments by homologous and heterologous recombination of purified polypeptides. The Journal of Cell Biology 1985:101(5):1826-41.

[6] Morgan PR, Shirlaw PJ, Johnson NW, et al. Potential applications of antikeratin antibodies in oral diagnosis. J Oral Pathol 1987;16(4):212-22.

[7] Rugg EL, McLean WH, Allison WE, et al. A mutation in the mucosal keratin $\mathrm{K} 4$ is associated with oral white sponge nevus. Nat Genet 1995;11(4):450-2.

[8] Richard G, De Laurenzi V, Didona B, et al. Keratin 13 point mutation underlies the hereditary mucosal epithelial disorder white sponge nevus. Nat Genet 1995;11(4):4535 .

[9] Bolling MC, Lemmink HH, Jansen GHL, et al. Mutations in KRT5 and KRT14 cause epidermolysis bullosa simplex in 75\% of the patients. Br J Dermatol 2011;164(3):637-44.

[10] Almutawa F, Thusaringam T, Watters $\mathrm{K}$, et al. pachyonychia congenita (k16) with unusual features and good response to acitretin. Case Rep Dermatol 2015;7(2):220-6.

[11] Jordan RCK, Daniels TE, Greenspan JS, et al. Advanced diagnostic methods in oral and maxillofacial pathology. Part II: immunohistochemical and Immunofluorescent methods. Oral Surg Oral Med Oral Pathol Oral Radiol Endol 2002;93(1):56-74.

[12] Ram Prasad VVS, Nirmala NR, Kotian MS. Immunohistochemical evaluation of expression of cytokeratin 19 in different histological grades of leukoplakia and oral squamous cell carcinoma. Indian J Dent Res 2005;16(1):6-11.

[13] Mujyambere B, Jayaraj R, Suja S. Cytokeratin 19 (CK19) as a marker for epithelial differentiation and malignant 
transformation: its clinical relevance in diagnosis, prognosis and treatment response monitoring. IRE Journals 2018;2(3):51-61.

[14] Yamashina M, Sato K, Tonogi M, et al. Evaluation of superficial oral squamous cell malignancy based on morphometry and immunoexpression of cytokeratin 13 and cytokeratin 17. Acta Cytol 2014;58(1):67-75.
[15] Miettinen M. Immunohistochemistry in Oral Pathology:an adjunct tool in tumour typing. Oral and MaxillofacSurg Clin North Am 1994;6(3):391-400.

[16] de AraújoVC,de SousaSo. Expression of different keratins in salivary gland tumours. Eur J Cancer B Oral Oncol 1996;32(1):14-8.

[17] Sabrina N, Delmira A, Gabriel T, et al. Cytokeratins 14 and 19 in odontogenic cysts and tumours: a review.Odontoestomatología 2014;16(24):45-55. 